\title{
Efeito de velocidades de rebaixamento do nível freático em diferentes períodos de desenvolvimento da cultura da alface
}

\author{
Rafael Mingoti ${ }^{1}$, Pablo A. N. Flecha ${ }^{2}$, Sérgio N. Duarte ${ }^{3} \&$ Décio E. Cruciani ${ }^{3}$
}

\begin{abstract}
RESUMO
Através deste trabalho objetivou-se determinar os efeitos do encharcamento do solo nas variáveis fenológicas e na produtividade da cultura da alface, identificar o estádio fenológico em que ocorre a maior diminuição da produtividade e obter uma relação entre a produtividade relativa da cultura e o índice diário de estresse. O delineamento experimental adotado foi inteiramente casualizado, arranjado em esquema fatorial $[(3 x 4)+1]$, com 3 repetições. Os tratamentos consistiram do período de inundação $(12,22$ e $32 \mathrm{DAT})$, de velocidades de rebaixamento do nível freático $(30 \mathrm{~cm}$ em 24 , 48, 72 e 96 horas) e uma testemunha, na qual não foi aplicado estresse por elevação do lençol freático. A alface apresentou-se como cultura sensível ao encharcamento; entretanto, não foi possível se definir um valor para o coeficiente de drenagem pois, mesmo com a maior velocidade de rebaixamento testada, ocorreu decréscimo de cerca de $50 \%$ da produção. Dentre os três períodos nos quais o estresse causado pela elevação do nível freático foi aplicado, o primeiro foi o que ocasionou maiores perdas. A produtividade das plantas de alface apresentou correlação linear negativa com 0 índice diário de estresse (IDS).
\end{abstract}

Palavras-chave: drenagem, inundação, estresse hídrico

\section{Effect of water table drawdown velocities in different stages of lettuce crop}

\begin{abstract}
The work had the objectives of determining the effect of water table drawdown velocities on the growth and yield of lettuce crop in a flooded soil, identifying the stage of the crop cycle with the highest reduction in the productivity and obtaining a relation between the crop relative productivity and the daily stress index. The statistical experimental design was completely randomized in factorial scheme $[(3 \times 4)+1]$, with three replications. The water table was lowered at 3 stages of the crop cycle $(12,22$ and 32 days after the transplanting), four drawdown velocities ( $30 \mathrm{~cm}$ during $24,48,72$ and $96 \mathrm{~h}$ ) and a 13 treatment in which stress was not applied with the elevation of the water table. The lettuce presented as a sensible crop to the water-logging, although, it was not possible to define a value for the drainage coefficient because the highest drawdown velocity tested presented $50 \%$ of loss in the yield. Among the three crop stages in witch the stress caused by the water table elevation was applied, the first one caused the highest loss in the yield. The relative yield of lettuce plant had a negative linear relation with the daily stress index.
\end{abstract}

Key words: drainage, water-logging, water-stress

${ }^{1}$ Graduando em Engenharia Agronômica, ESALQ-USP, Av. Humberto Cereser 2453, casa 1 - Caxambu, Jundiaí,SP. CEP. 13216-700. Fone: (19) 8138-0284.Email: ramingoti@uol.com.br.

${ }^{2}$ Mestrando em Irrigação e Drenagem ESALQ-USP, R. Edu Chaves 1134, São Dimas, Piracicaba, SP. CEP. 13416-020. Fone: (19)3432-6704. E-mail: panflecha@yahoo.com.br.

${ }_{3}^{3}$ Depto. de Engenharia Rural ESALQ-USP. Av. Pádua Dias 11 - Agronomia, Piracicaba,SP. CEP. 13418-900. Fone: (19) 3429-4217 ramal 251. E-mail: snduarte@esalq.usp.br. 


\section{INTRODUÇÃO}

O cultivo em solos onde as condições não são ideais para as culturas, como em solos hidromórficos apresenta-se, muitas vezes, como opção de expansão da área agricultável economicamente viável. Algumas espécies cultivadas encontram, nesses ambientes, condições favoráveis ao seu desenvolvimento, como alta umidade na camada superficial do solo, mas para a maioria das espécies de interesse comercial incluindo-se as hortaliças, é necessário um controle do lençol freático.

A alface (Lactuca sativa L.) destaca-se como a principal hortaliça folhosa cultivada no Brasil. Ocupa uma área de aproximadamente 31.000 ha e constitui um agronegócio que movimenta R $\$ 2$ bilhões ano-1 ${ }^{-1}$ com a geração de cinco empregos diretos por hectare (Teixeira Yañez et al., 2003).

Em solos hidromórficos, a drenagem é imprescindível para que o cultivo de espécies como a alface, seja realizado, permitindo que se promova a remoção do excesso de água acumulada na superfície e no perfil do solo, de forma a aumentar a taxa de difusão de oxigênio, que chega a valores de menos de 20\%, em um solo encharcado, após $24 \mathrm{~h}$ (Mukhtar et al., 1996); no entanto, ainda são necessárias maiores informações sobre essas culturas para que se tenha o correto dimensionamento dos sistemas de drenagem, destacando-se o conhecimento da velocidade de rebaixamento do nível freático que o sistema deve ser capaz de proporcionar para que não ocorra o comprometimento da produtividade (Scott, 1989; Sá et al., 2002).

A sensibilidade das culturas ao excesso de umidade é dependente do clima e do estágio fenológico em que a inundação acontece. No que diz respeito ao segundo aspecto, experimentos realizados no Brasil com as culturas do trigo, feijão, pimentão e milho, revelaram que a floração é o estádio em que o encharcamento causa maior redução de produtividade e que, no estádio final do ciclo, o efeito adverso do encharcamento diminui (Cruciani, 1981; Silva, 1982; Cruciani \& Minami, 1982; Cruciani, 1985). Para culturas cujo ciclo comercial não chega a atingir o florescimento, como a alface, poucos são os relatos na literatura a respeito do estádio mais sensível. Vildoso (1995), trabalhando com a cultura da cenoura em lisímetros, imprimiu estresses por elevação do lençol freático com três dias de duração, aplicados aos 8, 33 e 63 dias após a semeadura. Os resultados revelavam que a cultura foi mais sensível ao encharcamento ocorrido no primeiro estádio. Por outro lado, Costa et al. (2003), procedendo de forma semelhante em três fases do ciclo da cultura da beterraba, observaram maiores reduções na produtividade das plantas submetidas ao encharcamento ocorrido na terceira fase.

Hiler (1969) idealizou o conceito do Índice Diário de Estresse (IDS) que permite determinar o grau de estresse imposto a uma cultura durante diferentes estádios de desenvolvimento. O IDS é aplicável não só para caracterizar as necessidades de irrigação como, também, as de drenagem servindo, então, para avaliar tanto os efeitos da deficiência quanto do excesso de água no solo.

Com o avanço das técnicas de programação de computa- dores nas últimas décadas, surgiram vários modelos para avaliação do desempenho de sistemas de drenagem como o Drainmod (Skaggs, 1981), o Simdreno (Duarte et al., 1998) e o Sisdrena (Miranda et al., 1998), entre outros, os quais simulam a flutuação do lençol freático para diferentes combinações entre espaçamento e profundidade de drenos, para uma série de dados meteorológicos de vários anos. Fazendo-se uso de relações experimentais entre a produtividade da cultura e o IDS, estima-se a produção obtida para cada ano, o que permite identificar qual dos sistemas testados se apresenta como o mais econômico.

Neste trabalho, objetivou-se determinar os efeitos de quatro diferentes velocidades de rebaixamento do nível freático nas variáveis fenológicas e na produtividade da cultura da alface, identificar o estádio fenológico em que ocorre a maior diminuição da produtividade devido à inundação e obter uma relação entre a produtividade relativa da cultura e o índice diário de estresse.

\section{MATERIAL E MÉTODOS}

Conduziu-se um experimento em campo aberto, na área experimental do Departamento de Engenharia Rural da ESALQ/USP, em Piracicaba, SP. As unidades experimentais, denominadas lisímetros, foram construídas através de tubos de concreto impermeabilizados com produto comercial denominado Cicaflex; possuíam 0,4 m de diâmetro interno e $1,2 \mathrm{~m}$ de altura. Os tubos de concreto foram assentados diretamente no solo e suas bases e paredes laterais impermeabilizadas, a fim de se evitar perda de água por infiltração. Para a admissão de água e para a drenagem, próximo à base cimentada dos lisímetros foram feitos orifícios nos quais se inseriram tubos de PVC de 0,0125 m de diâmetro; estes por sua vez, apresentavam comprimento de $0,60 \mathrm{~m}$, com furos de 0,010 m de diâmetro em seu perímetro, espaçados 0,10 m. Para facilitar a drenagem e evitar o carreamento de solo utilizou-se, como material filtrante, manta sintética não-tecida (Bidim OP-20) e uma camada de 0,15 m de brita número 1. A distribuição da água, partindo de 2 caixas de cimento amianto interconectadas para a bateria de lisímetros, foi feita

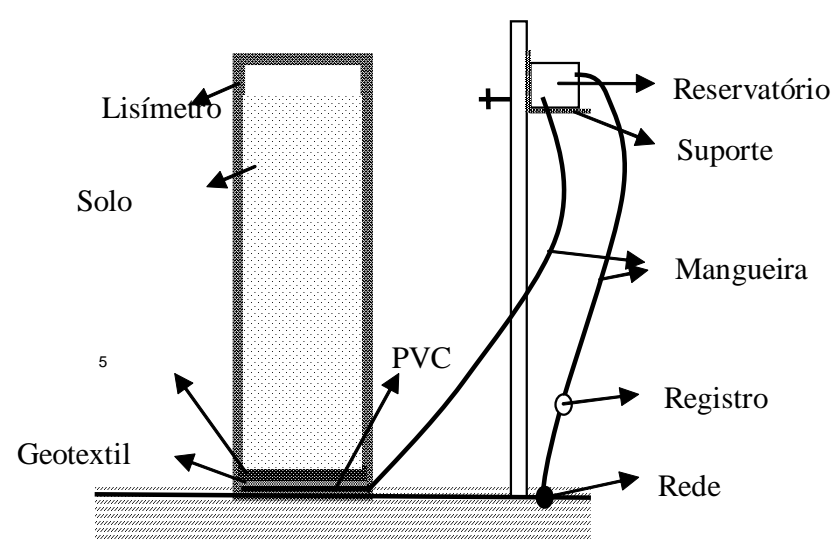

Figura 1. Representação gráfica dos elementos utilizados na inundação dos vasos 
Tabela 1. Análise química do solo utilizado no experimento

\begin{tabular}{|c|c|c|c|c|c|c|c|c|c|}
\hline \multirow{2}{*}{$\left.(\mathrm{pH} \mathrm{CaCl})_{2}\right)$} & \multirow{2}{*}{$\begin{array}{l}\text { M.O. } \\
\left(\mathrm{g} \mathrm{dm}^{-3}\right)\end{array}$} & $P$ & \multirow[t]{2}{*}{ s } & K & $\mathrm{Ca}$ & Mg & $\mathrm{H}+\mathrm{Al}$ & $T$ & \multirow{2}{*}{$\begin{array}{c}V \\
(\%)\end{array}$} \\
\hline & & $\left(\mathrm{mg} \mathrm{dm}^{-3}\right)$ & & \multicolumn{5}{|c|}{$\left.(\mathrm{mmolc} \mathrm{dm})^{-3}\right)$} & \\
\hline 5,6 & 16 & 357 & 623 & 15,2 & 69 & 16,2 & 16 & 115 & 87 \\
\hline
\end{tabular}

por gravidade, através de uma rede de tubos de PVC e de polietileno, ambos com 0,025 m de diâmetro, enterrados a $0,20 \mathrm{~m}$ de profundidade. Os tubos de polietileno foram seccionados a cada 0,6 m para a colocação de uma derivação à qual se acoplava uma mangueira cristal de 0,0125 m conectada a um registro de PVC. As mangueiras foram acopladas a pequenos reservatórios cilíndricos, confeccionados em PVC, providos com chave-bóia, com diâmetro e altura de 0,30 m. Referidos reservatórios se destinavam a controlar e manter constante o nível freático no interior dos lisímetros, individualmente, durante a realização dos tratamentos, conforme se observa na Figura 1.

Os lisímetros foram preenchidos com material de solo proveniente de um perfil classificado como Latossolo Vermelho-Amarelo Álico (EMBRAPA, 1999), previamente homogeneizado, que apresentava $71 \%$ de areia, $7 \%$ de silte e $22 \%$ de argila; posteriormente, realizou-se adubação do solo, com base na análise química, cujo resultado é apresentado na Tabela 1, empregando-se cloreto de potássio, uréia e superfosfato simples.

Adotou-se a cultivar de alface 'Verônica', sendo cultivada uma planta por lisímetro. O transplantio foi realizado no dia 8 de dezembro de 2001, utilizando-se mudas com 24 dias de idade, procedendo-se à colheita 41 dias após. Durante todo o ciclo foram realizados os tratos culturais necessários ao pleno desenvolvimento da cultura (controle de pragas e doenças e retirada de plantas daninhas) e, também, realizada irrigação diária, exceto nas parcelas experimentais, durante o período em que estavam sendo aplicados os tratamentos.

O delineamento experimental adotado foi o inteiramente casualizado, arranjado em esquema fatorial [(3 x 4) + 1], totalizando 13 tratamentos com 3 repetições. Os tratamentos consistiram em: períodos de aplicação do encharcamento: 12 dias após o transplante (DAT), 22 DAT e 32 DAT (denominados P1, P2 e P3, respectivamente); velocidades de rebaixamento do nível freático: rebaixamento a uma profundidade de $30 \mathrm{~cm}$ em 24, 48, 72 e $96 \mathrm{~h}$ (denominados V1, V2, V3 e V4, respectivamente); testemunha na qual não

Tabela 2. Esquema da análise de variância utilizada

\begin{tabular}{|c|c|}
\hline Fonte de Variação & G.L. \\
\hline Testemunha & 1 \\
\hline Velocidade de rebaixamento & 3 \\
\hline Período de aplicação & 2 \\
\hline Interação velocidade* período & 6 \\
\hline Tratamentos & 12 \\
\hline Resíduo & 25 \\
\hline Total & $37\left(^{*}\right)$ \\
\hline
\end{tabular}

(*) Devido à ocorrência de uma parcela perdida, o grau de liberdade total do experimento foi de 37 ao invés de 38 foi aplicado estresse por elevação do lençol freático (denominada $\mathrm{T}$ ).

Na Tabela 2 tem-se o esquema da análise de variância utilizado, através do qual se pode destacar a presença de um tratamento extra na análise (testemunha). Esta análise foi feita empregando-se o esquema descrito por Perecin et al. (2000).

$\mathrm{Na}$ análise de variância empregou-se o teste $\mathrm{F}$ e para a comparação das médias dos tratamentos optou-se pelo teste de Duncan para o nível de probabilidade de 5\%.

Para se considerar o fato de que o rebaixamento do lençol freático em áreas drenadas não se dá linearmente, calcularamse as posições intermediárias do nível freático para cada velocidade de rebaixamento, pela equação de Boussinesg \& Glover (van Schilfgaarde, 1974). O nível freático foi rebaixado a cada 12 horas, conforme apresentado na Tabela 3.

Após a colheita foram avaliadas, para cada parcela, as seguintes variáveis: altura da parte aérea, obtida com a medição da maior distância da parte aérea até o nível do solo, utilizando-se uma régua graduada em centímetros; diâmetro da 'cabeça', medida com a utilização de uma régua graduada em centímetros; diâmetro do caule, obtido com a medição do diâmetro do caule na altura do colo da planta, com a utilização de um paquímetro analógico; peso 'fresco' da parte aérea, obtido com a pesagem de todo o material verde de folhas e caule de cada parcela, realizado através de uma balança digital, com precisão de 0,01 g; peso 'seco’ da parte aérea, obtido com a pesagem deste material 'verde', após a sua secagem em estufa a $60{ }^{\circ} \mathrm{C}$ e ventilação forçada, até a obtenção de um peso constante.

O índice de estresse diário (IDS), proposto por Hiler (1969) foi obtido pela Eq. 1:

$$
\text { IDS }=\sum_{\mathrm{i}=1}^{\mathrm{n}}\left(\mathrm{SC}_{\mathrm{i}} \mathrm{SEW}_{30}\right)
$$

Tabela 3. Profundidades do nível freático $(\mathrm{cm})$ segundo as diferentes velocidades de rebaixamento

\begin{tabular}{ccccc}
\hline $\mathbf{T}$ (Dias) & \multicolumn{4}{c}{ Velocidades de Rebaixamento } \\
& V1 & V2 & V3 & V4 \\
\hline 0,5 & 17,7 & 9,7 & 6,7 & 5,1 \\
\hline 1 & 30,0 & 17,6 & 12,5 & 9,7 \\
\hline 1,5 & 39,2 & 24,3 & 17,6 & 13,9 \\
\hline 2 & 46,2 & 30,0 & 22,2 & 17,7 \\
\hline 2,5 & 51,8 & 34,9 & 26,3 & 21,1 \\
\hline 3 & 56,3 & 39,1 & 30,0 & 24,3 \\
\hline 3,5 & 60,0 & 42,8 & 33,3 & 27,3 \\
\hline 4 & 63,2 & 46,1 & 36,4 & 30,0 \\
\hline 4,5 & fundo & fundo & fundo & fundo \\
\hline
\end{tabular}


em que n é o número de estádios de desenvolvimento, SC é o coeficiente de sensibilidade da cultura e $\mathrm{SEW}_{30}$ é o somatório das alturas diárias do lençol freático acima da profundidade de $30 \mathrm{~cm}$. O coeficiente de sensibilidade da cultura foi determinado para os três períodos de aplicação dos tratamentos, pela Eq. 2:

$$
\mathrm{SC}_{\mathrm{i}}=\frac{\left(\mathrm{Y}-\mathrm{Y}_{\mathrm{i}}\right)}{\mathrm{Y}}
$$

em que Y é a produção de matéria verde da parte aérea obtida nas plantas não inundadas (testemunha) e $\mathrm{Y}_{\mathrm{i}}$ é a produção de matéria verde da parte aérea das plantas submetidas a inundação do solo no período i.

$\mathrm{O}$ índice $\mathrm{SEW}_{30}$ foi obtido pela Eq.3:

$$
\mathrm{SEW}_{30}=\sum_{\mathrm{i}=1}^{\mathrm{n}}\left(30-\mathrm{X}_{\mathrm{i}}\right)
$$

em que n é o número de dias em que o nível freático, durante o ciclo da cultura, permanece acima de $30 \mathrm{~cm}$ de profundidade, e $\mathrm{X}_{\mathrm{i}}$ profundidade do nível freático abaixo da superfície do solo no dia i, em $\mathrm{cm}$.

Com base nas posições do nível freático para as diferentes velocidades de rebaixamento, obtiveram-se cinco valores de $\mathrm{SEW}_{30}: \mathrm{SEW}_{30}=0$ - para o tratamento testemunha e $\mathrm{SEW}_{30}=21,15 ; 34,20 ; 47,35$ e $60,45 \mathrm{~cm} \mathrm{~d}^{-1}$ para os tratamentos V1, V2, V3 e V4, respectivamente.

A combinação de quatro velocidades de rebaixamento com os três períodos de aplicação mais a testemunha, resultou em 13 valores de IDS, que foram correlacionados com as respectivas produtividades relativas, tomando-se como base o peso fresco da parte aérea da testemunha, considerado igual a $100 \%$.

\section{RESULTADOS E DISCUSSÃO}

O resultado da análise da variância de todas as variáveis analisadas está apresentado, de forma resumida, na Tabela 4, na qual se pode observar que não houve variável que tenha apresentado a interação velocidade $\mathrm{x}$ período com um valor $\mathrm{F}$ significativo em nível de $5 \%$ de probabilidade. Verifica-se, também, em todas as variáveis analisadas, diferença

Tabela 4. Valores de F para. cada variável estudada

\begin{tabular}{cccccc}
\hline $\begin{array}{c}\text { Coeficiente } \\
\text { da Variação }\end{array}$ & Altura & $\begin{array}{c}\text { Diâmetro } \\
\text { da cabeça }\end{array}$ & $\begin{array}{c}\text { Diâmetro } \\
\text { do caule }\end{array}$ & Peso verde & Peso seco \\
\cline { 2 - 6 } & $10,52^{* *}$ & $12,05^{* *}$ & $6,21^{*}$ & $26,68^{* *}$ & $30,86^{* *}$ \\
$\begin{array}{c}\text { Testemunha } \\
\text { todos }\end{array}$ & 2,56 & 1,59 & $3,54^{*}$ & 2,07 & 2,07 \\
\hline $\begin{array}{c}\text { Velocidade } \\
\text { Período }\end{array}$ & $9,15^{* *}$ & 3,72 & $5,95^{* *}$ & $5,74^{\star *}$ & $8,77^{* *}$ \\
$\begin{array}{c}\text { Interação velocidade* } \\
\text { período }\end{array}$ & 0,62 & 0,37 & 0,74 & 0,54 & 0,78 \\
\hline
\end{tabular}

* Significativo em nível de $5 \%$ de probabilidade;

** Significativo em nível de $1 \%$ de probabilidade entre a testemunha e pelo menos um dos outros tratamentos envolvidos. No que diz respeito ao fator Período, somente para a variável diâmetro da "cabeça” não se obteve um valor de $\mathrm{F}$ que não fosse significativo a $1 \%$ de probabilidade; já para o fator velocidade só foram encontradas diferenças significativas para a variável diâmetro do caule.

Os valores das médias das variáveis analisadas são apresentados, na forma de gráfico (Figura 2). Nesses gráficos, as letras sobre as colunas representam o resultado do teste de comparação de médias de Duncan, realizado a 5\% de significância dentro de cada fator (períodos e velocidades) isoladamente, pois as interações entre os fatores não foram significativas.

Atentando-se para os resultados do teste de comparação de médias de Duncan, para a variável altura da parte aérea, apresentados na Figura 2, pode-se constatar que houve diferença significativa entre a testemunha e os tratamentos relativos às velocidades de rebaixamento mais lentos (V3 e V4) e entre esta e os tratamentos aplicados no primeiro período. Quando se comparam os três períodos, independentemente da testemunha, o teste de Duncan não consegue acusar diferenças, embora estas tenham sido identificadas no teste $\mathrm{F}$, devido à diferença entre a média do fatorial e a média da testemunha serem muito discrepantes, ocasionando diferença significante no teste $\mathrm{F}$, mesmo quando se compara a testemunha com os níveis deste fator.

Já na variável diâmetro da 'cabeça', cujas médias são apresentadas na Figura 2, pode-se observar que os resultados são semelhantes àqueles apresentados na variável altura da parte aérea. Embora não significativa, verifica-se tendência mais nítida de diminuição do diâmetro da 'cabeça' da alface, à medida que as velocidades de rebaixamento são menores.

A Figura 2 mostra o resultado da comparação de médias do diâmetro do caule pelo teste de Duncan. Esta variável se apresenta um pouco menos sensível às diferentes velocidades de rebaixamento, pois a testemunha só difere significativamente de V4. O período P1, tal como verificado nas duas variáveis anteriores, demonstra ser o mais crítico. Observase, ainda, que o teste de Duncan não foi capaz de revelar as diferenças entre as quatro velocidades e os três períodos, muito embora estas tenham sido apontadas pelo teste $\mathrm{F}$.

O efeito dos tratamentos sobre a variável peso fresco da parte aérea é apresentado na Figura 2, observando-se que o efeito dos tratamentos sobre esta variável é mais drástico, ou seja, a testemunha difere significativamente de todos os tratamentos relativos às velocidades e períodos. Considerandose que esta é a variável mais importante, verifica-se que, mesmo com a velocidade de rebaixamento mais alta (V1 - $30 \mathrm{~cm}$ em 1 dia) o peso fresco da parte aérea foi cerca da metade do peso da testemunha, o que está em concordância com Cruciani \& Minami (1982) que relataram a grande sensibilidade das hortaliças ao encharcamento. Estudando a suscetibilidade do pimentão a inundações temporárias, esses autores encontraram que o tempo de drenagem da zona radicular deve ser inferior a 2 dias. Há necessidade, portanto, de se testar velocidades de rebaixamento ainda maiores, para se definir o coeficiente de drenagem. Embora o teste de 

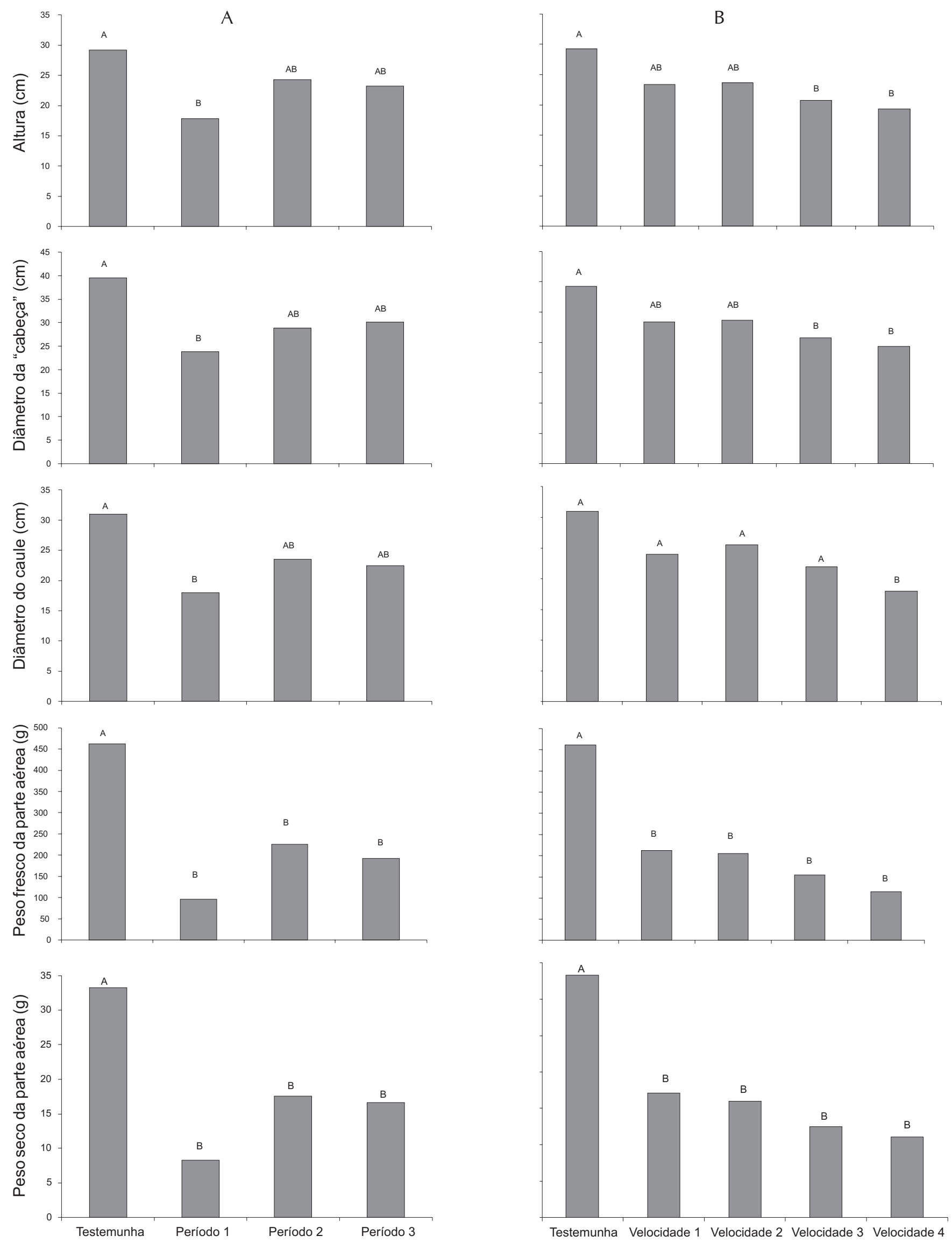

Figura 2. Valores médios de altura, diâmetro da cabeça, diâmetro do caule, peso fresco e seco da parte aérea das plantas nos tratamentos em função de períodos (A) e velocidades de rebaixamento (B)

R. Bras. Eng. Agríc. Ambiental, v.10, n.1, p.10-16, 2006. 
Duncan não revele diferenças entre os períodos de aplicação, diferença esta acusada no teste $\mathrm{F}$, o período 1 apresenta-se como o mais crítico, tal qual foi observado para as outras variáveis.

As médias do peso seco da parte aérea para os diferentes tratamentos, são apresentadas na Figura 2. Como previsto, a tendência é a mesma verificada para a variável peso fresco. Os menores valores observados para os tratamentos aplicados no período 1 concordam com os resultados observados por Vildoso (1995) para a cultura da cenoura. A grande sensibilidade ao encharcamento, revelada para a cultura da alface, mesmo para condições em que o nível freático é rebaixado rapidamente (V1), leva a se supor que evitar que o lençol atinja a superfície do solo após uma recarga intensa, com o plantio sobre canteiros, por exemplo, pode apresentar-se como melhor opção prática.

Os valores dos coeficientes de sensibilidade da cultura (SC) calculados pela Eq. 2 traduzem, numericamente, o efeito dos períodos de aplicação do encharcamento apresentados na Figura 2. Os valores de SC são maiores nos períodos mais críticos. O coeficiente SC médio para o primeiro estádio foi de 0,79 e apresentou variações de 0,61 a 0,90 . No segundo estádio, SC variou de 0,37 a 0,71 sendo, neste estádio, SC médio igual a 0,51 . No terceiro estádio, SC oscilou de 0,53 a 0,64 sendo, neste estádio, SC médio igual a 0,58 . Tais resultados revelam que a quebra de produção devido aos encharcamentos proporcionados nos $1^{\circ}, 2^{\circ}$ e $3^{\circ}$ períodos, foi de 79, 51 e 58\%, respectivamente.

A Figura 3 mostra a regressão entre a produtividade relativa e o índice de estresse (IDS). O modelo linear foi o que apresentou melhor ajuste, em concordância com trabalhos realizados com outras culturas, como soja (Scott et al., 1989), milho (Mukthar et al., 1990), cenoura (Vildoso, 1995) e ervilha (Sá, 2002).

A reta pontilhada representa aquela que fornece o maior coeficiente de determinação $\left(\mathrm{R}^{2}\right)$. Segundo a equação desta reta, para um valor nulo de IDS (ausência total de estresse), obtém-se uma produtividade relativa de apenas 79,9\%, o que não está de acordo com o modelo proposto por Hiler (1969). Impondo-se a condição da reta passar pelo

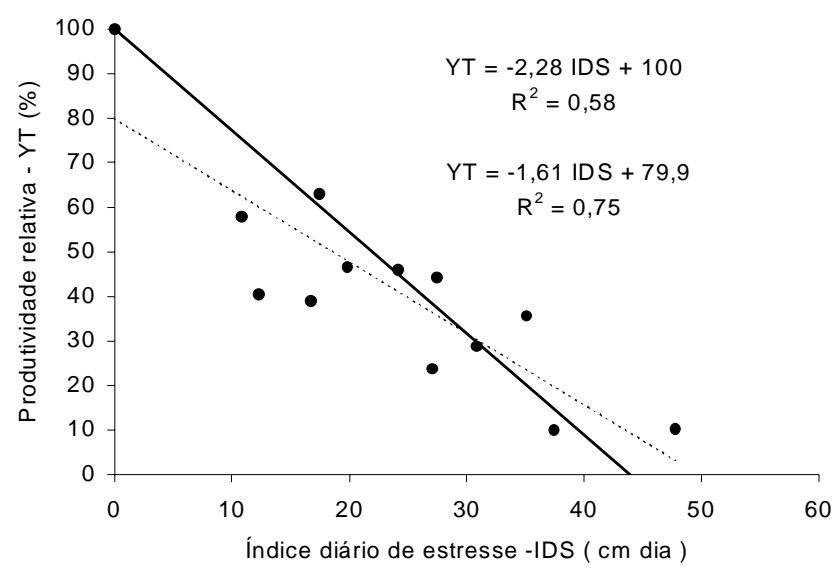

Figura 3. Peso fresco relativo da parte aérea da alface (YT) relacionado ao índice diário de estresse (IDS) ponto correspondente à testemunha [IDS =0; YT = 100\%], obter-se-á uma segunda equação (YT = 100 - 2,28 IDS) que, embora possua $\mathrm{R}^{2}$ mais baixo $(0,5807)$ poderá ser utilizada como uma primeira aproximação por modelos de simulação de desempenho de sistemas de drenagem, para o dimensionamento de projetos nos quais a alface seja uma das culturas de interesse.

\section{CONCLUSÕES}

1. A alface apresentou-se como uma cultura sensível ao encharcamento.

2. Não foi possível definir um valor para o coeficiente de drenagem porque, mesmo com a maior velocidade de rebaixamento testada (30 cm em 24 h) ocorreu decréscimo de cerca de $50 \%$ da produção.

3. Dentre os três períodos nos quais o estresse causado pela elevação do nível freático foi aplicado, o primeiro (dos 12 a 15 DAT) foi o que ocasionou maiores perdas.

4. A produtividade das plantas de alface apresentou correlação linear negativa com o índice diário de estresse (IDS).

\section{AGRADECIMENTOS}

Extensivos especialmente ao Professor Doutor Antonio Augusto Franco Garcia, do Departamento de Genética da ESALQ/USP, pela ajuda na análise estatística do experimento, imprescindível para a conclusão do artigo.

Ao Departamento de Engenharia Rural da ESALQ-USP, pelo inestimável apoio, e ao Grupo de Práticas em Irrigação e Drenagem da ESALQ-USP, pelo incentivo.

\section{LITERATURA CITADA}

Costa, R. N. T.; Vasconcelos, J. P.; Silva, L. A.; Ness, R. L. L. Efeitos do excesso de água no solo sobre componentes de produção da beterraba. In: Congresso Brasileiro de Engenharia Agrícola, 32, 2003, Goiânia. Anais... Goiânia: SBEA, 2003, CD Rom.

Cruciani, D. E. Caracterização agronômica de coeficientes de drenagem para elaboração de projetos. In: Simpósio Brasileiro de Hidrologia e Recursos Hídricos, 4, 1981, Fortaleza. Anais...Fortaleza: ABRH, 1981. p.500-514

Cruciani, D. E. Caracterização agronômica do coeficiente de drenagem para elaboração de projetos com a cultura do milho (Zea mays L.) Revista Item, Brasília, n.22, p.28-31, 1985.

Cruciani, D. E.; Minami, K. Susceptibilidade do pimentão (Capsicum annum L.) a inundações temporárias do sistema radicular. Anais da ESALQ, Piracicaba, v.39, p.137-150, 1982.

EMBRAPA - Empresa Brasileira de Pesquisa Agroipecuária. Sistema brasileiro de classificação de solos. Brasília: EMBRAPA - Produção de Informação, 1999. 67p. 
Duarte, S. N. ; Ferreira, P. A.; Pruski, F. F.; Martinez, M. A. Modelo para avaliação de desempenho de sistemas de drenagem subterrânea e cálculo de espaçamento de drenos. Parte 1: desenvolvimento e análise de sensibilidade. Engenharia Agrícola. Jaboticabal, v.18, n.2, p.19-31, 1998.

Hiler, E. A. Quantitative evaluation of crop drainage requirements. Transactions of the ASAE, St Joseph, v.12, n.4, p.499505, 1969.

Miranda, J. H.; Duarte, S. N.; Folegatti, M. V. Modelo para simulação da dinâmica da água em sistemas de drenagem subterrânea. Engenharia Rural, Piracicaba, v.9, n.2, p.1-10, 1998.

Mukhtar, S.; Baker, J. L.; Kanwar, R. S. Corn growth as affected by excess soil water. Transactions of the ASAE, St Joseph, v.33, n.2, p.437-442, 1990.

Mukhtar, S.; Baker, J. L.; Kanwar, R. S. Effect of short-term flooding and drainage on soil oxygenation. Transactions of the ASAE, St Joseph, v.39, n.3, p.915-920, 1996.

Perecin, D.; Malheiros, E. B.; Pereira, G. T. Variáveis auxiliares para expressar desdobramentos de graus de liberdade e contrastes com o programa SAS. In: Congresso da Região Brasileira da Sociedade Internacional de Biometria, 45, 2000, São Carlos. Resumos... São Carlos: 2000. p.137-140
Sá, J. S.; Cruciani, D. E.; Duarte, S. N. Índice diário de estresse hídrico da cultura de ervilha. In: Congresso Nacional de Irrigação e Drenagem, 12, 2002, Uberlândia. Anais... Uberlândia: ABID, 2002. CD Rom.

Scott, H. D.; De Angulo, J.; Daniels, M. B.; Wood, L. S. Flood duration effects on soybean growth and yield. Agronomy Journal, Madison, v.81, n.2, p. 631-636, 1989.

Silva, A. S. O pro-várzeas em propriedades selecionadas do município de Curvelo-MG. Viçosa: UFV, 1982. 77p. Dissertação Mestrado

Skaggs, R. W. DRAINMOD - Reference report: methods for design and evaluation of drainage-water management systems for soils with high water tables. Raleigh: USDA-SCS, 1981. 329p.

Teixeira Yañez, L. D.; Sala , F. C.; Costa, C. P.; Kimati, H. Revista Cultivar Hortaliças e Frutas, Piracicaba, v.21, n.5, p.1721, 2003.

van Schilfgaarde, I. Nonsteady flow to drains. In: van Schilfgaarde, I. Drainage for agriculture. Madison: American Society of Agronomy, 1974. p.245-270.

Vildoso, T. A. Relação entre a produção relativa e o índice diário de stress para a cultura da cenoura (Daucus carota L.). Viçosa: UFV, 1995. 43 p. Dissertação Mestrado 